\title{
Impact of the American Stop Smoking Intervention Study on cigarette consumption
}

Marc W Manley, John P Pierce, Elizabeth A Gilpin, Bradley Rosbrook, Charles Berry, Lap-Ming Wun

\begin{abstract}
Objective-To obtain an early estimate of the effectiveness of the American Stop the effectiveness of the Amering Intervention Study (ASSIST).

Design, setting, and participantsSeventeen American states funded through ASSIST are compared with 32 others regarding per capita cigarette consumption from 1989 to 1995. California, which already had an extensive tobacco control programme, was omitted. ASSIST states were selected competitively (not randomly) based on their proposals' merit, state smoking prevalence, and geographical distribution.
\end{abstract}

Interventions-Comprehensive tobacco control programmes, emphasising policy interventions, were implemented in the ASSIST states beginning in 1993.

Main outcome measures-Trends in aggregated per capita cigarette consumption and inflation-adjusted average pricel pack of cigarettes in the intervention states were compared. Percentage change in per capita consumption is also compared with percentage change in inflation-adjusted cigarette price by state in each group from 1992 to 1994.

Results-Per capita consumption and inflation-adjusted cigarette price were nearly identical in both groups of states before 1993, when full funding for the ASSIST interventions began. However, by 1996 smokers in the intervention states were consuming about $7 \%$ less cigarettes per capita $(P<0.05$, beginning in 1994), and in 1994 the average price was over \$0.12/pack higher in the intervention states. All but three states (all intervention) showed decreases in cigarette price. Nonetheless, $76 \%$ of the intervention and $55 \%$ of the comparison states showed some decrease in consumption despite decreases in price. The relationship between changes in price and consumption was considerably diminished in the intervention group.

Conclusions-These interim results suggest that the ASSIST programme is associated with a substantial difference in tobacco consumption in a third of the United States, and that increased price from taxation may not be the only programme influence.

(Tobacco Control 1997;6 (suppl 2):S12-S16)

Keywords: ASSIST programme; cigarette consumption; tobacco tax
Introduction

Tobacco use has been identified as the leading preventible cause of death.' The National Cancer Institute (NCI) has sponsored more than a decade of research aimed at identifying the most effective ways to reduce tobacco use. This research suggests that comprehensive programmes that emphasise media and policy are the most promising intervention approaches in the current environment. ${ }^{2}$ Such statewide comprehensive programmes have been associated with a reduction in smoking in two states in Australia, ${ }^{34}$ and in California ${ }^{5}$ and Massachusetts. ${ }^{6}$

The American Stop Smoking Intervention Study for Cancer Prevention (ASSIST) is a phase $\mathrm{V}$ research initiative to develop, implement, and evaluate statewide tobacco $\overrightarrow{0}$ control projects. Phase $\mathrm{V}$ projects are designed to demonstrate that interventions are widely applicable to the population of the United States. It is one of the first demonstration projects of its kind that has been supported by the NCI.

In 1989, proposals for tobacco control programmes from state health departments were sought and reviewed both for their scientific merit and their ability to mobilise community coalitions. The selection process yielded 17 intervention states with a population base of 91 million people, closely reflecting the total American population in ethnic and geographical diversity. The ASSIST project began in 1991 under the direction of both the NCI and $\underline{0}$ the American Cancer Society (ACS).

Funding to support tobacco control programmes in each of the intervention states $\delta$ was set at a developmental or planning level for 1991 and 1992. Each state was required to 윽 have a coalition of organisations to guide the $\frac{7}{0}$ project under the leadership of the state health department and the state division of the ACS. $N$ Each state coalition developed a five-year com- N prehensive smoking control plan specifically N tailored to the needs of the state, but within the scientific guidelines provided by the NCI. The plans included goals related to public policy (clean indoor air, youth access, advertising, and tobacco taxes), mass media, and 0 programme services (such as smoking cessation classes). All states emphasised policy@ advocacy as the most effective and efficient $\stackrel{\Phi}{\varrho}$ type of activity. Programme staff and volunteers received extensive training in policy advocacy, media advocacy, coalition develop-0 ment, and other tobacco control topics. From 1993 to 1998 budgets were increased to? 
approximately $\$ 1$ million/year per state for programme implementation. All the intervention states were encouraged to use other funding to supplement this implementation budget whenever possible.

Evaluation of the effectiveness of tobacco control interventions in this phase $\mathrm{V}$ research project is complicated by the presence of other tobacco control interventions. For example, tobacco excise taxes have been increased in many states in the past five years, ${ }^{7}$ in some instances ostensibly for revenue generation. In a few states, additional elements of a comprehensive tobacco control programme have been funded by increased state tobacco taxes. The most prominent examples are the large programmes in California," Massachusetts, and Arizona. In addition, other agencies concerned with public health provide state-level funding for tobacco control programmes. The Centers for Disease Control and Prevention (CDC) and the Robert Wood Johnson Foundation (RWJ) provide such support for state programmes at a more modest annual level of $\$ 74000-\$ 300000$ per state. $^{1011}$

In this article, we present data depicting trends in per capita cigarette consumption and inflation-adjusted average cigarette price for the ASSIST intervention states and a comparison group of states. As California implemented a large and ongoing tobacco control programme funded by a substantial increase in its cigarette tax in 1989, we have omitted it from our comparison. Documentation of similar trends for the two groups of states in cigarette consumption and price before the start of this research project is important to the final evaluation of the effectiveness of the ASSIST interventions. We also examine the trends in per capita consumption through 1995 to identify whether the early years of the ASSIST intervention were associated with a significant difference in per capita consumption levels. Finally, we examine cigarette prices between 1989 and 1994 to assess differences between the two groups of states in this important aspect of the ASSIST intervention.

\section{Methods}

CIGARETTE CONSUMPTION AND PRICE DATA

The Tobacco Institute compiles and reports data on tax payments from all packages of cigarettes removed from wholesale warehouses to retail outlets within each state on a monthly basis. ${ }^{7}$ The reporting unit is the number of cigarette packs on which taxes were paid in any given month. Data from December 1984 through January 1996 are included in the present analysis. Although consumption estimates from this source are subject to monthly and seasonal variations that are business related rather than reflecting variation in consumption patterns, these data are gathered in a uniform manner across states and are the usual source for reporting national per capita consumption. Both the US Department of Agriculture and the US Surgeon General's reports on smoking and health use this data source. ${ }^{12-15}$
In this analysis we aggregate the consumption data from all states that received ASSIST funding (intervention group) and contrast it with the aggregated consumption data in states not receiving such funding (comparison group). We excluded California, which had a very large tobacco control programme during this period that was funded by an increase in its tobacco excise tax. ${ }^{5}$ Although Massachusetts, an ASSIST participant, also funds a tobacco control programme partly by a tax increase, it is retained in the analysis, because the impetus for the tax increase resulted from policy encouraged by the ASSIST intervention. ${ }^{\circ}$ The 17 states participating in ASSIST are: Colorado, Indiana, Maine, Massachusetts, Michigan, Minnesota, Missouri, New Jersey, New Mexico, New York, North Carolina, Rhode Island, South Carolina, Virginia, Washington, West Virginia, and Wisconsin (see map on page S8). The data for the District of Columbia were included in the comparison group of states.

The average price of a package of cigarettes (including state and federal excise taxes) as of 1 November of each year is published for each state annually, again by the Tobacco Institute. ${ }^{16}$ Data from November 1989 through November 1994 (the last year for which it was available) were analysed.

DATA ANALYSIS

Changes in total cigarette sales within a state may not be related to changes in smoking behaviour if the state population changed during the study period. We estimated per capita consumption for a given state in any given year using census estimates for the state population aged 18 years and older. We followed the Surgeon General's age criterion ${ }^{13}$ of 18 years because only about $1 \%$ of cigarettes sold in the United States are consumed by people aged 18 and younger. ${ }^{16} 17$ Decade census population data are as of 1 April for 1980 and 1990, and supplemental within-decade estimates are as of 1 July of each year. ${ }^{18} 19$ To obtain monthly estimates of state populations, we fit regression lines to the yearly data and interpolated.

Business-related variance in tax data occurs because of increased inventory clearance in the final month of any quarter (especially December) and corresponding reduced clearance in the first month of the quarter (particularly January). To partly remove this consistent pattern from the trend analyses, we consider six data points in each 12-month period which are computed by averaging the monthly results for December and January, February and March, ... October and November. Further, to assess trends over time, we applied the SABL seasonal and calendar adjustment procedure, available in the statistical package S-plus, ${ }^{20}{ }^{21}$ to these averaged bimonthly raw data points. The results from this procedure are called "deseasonalised" data.

To assess trends in the difference between the intervention and comparison states, the raw bimonthly data points for the intervention group were subtracted from those for the 


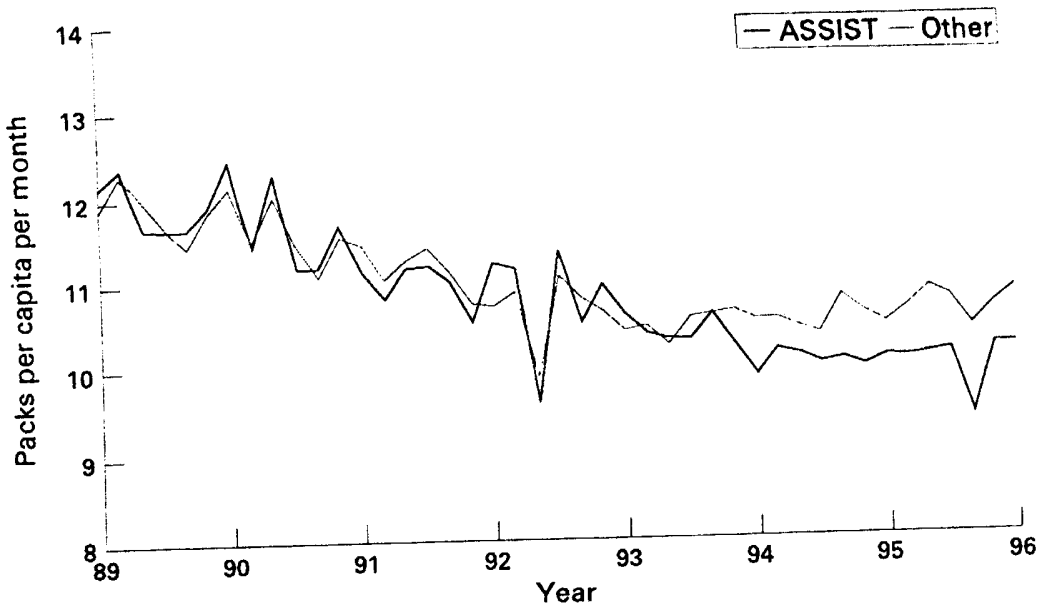

Figure 1 Deseasonalised per capita cigarette consumption for intervention and comparison states (excluding California).

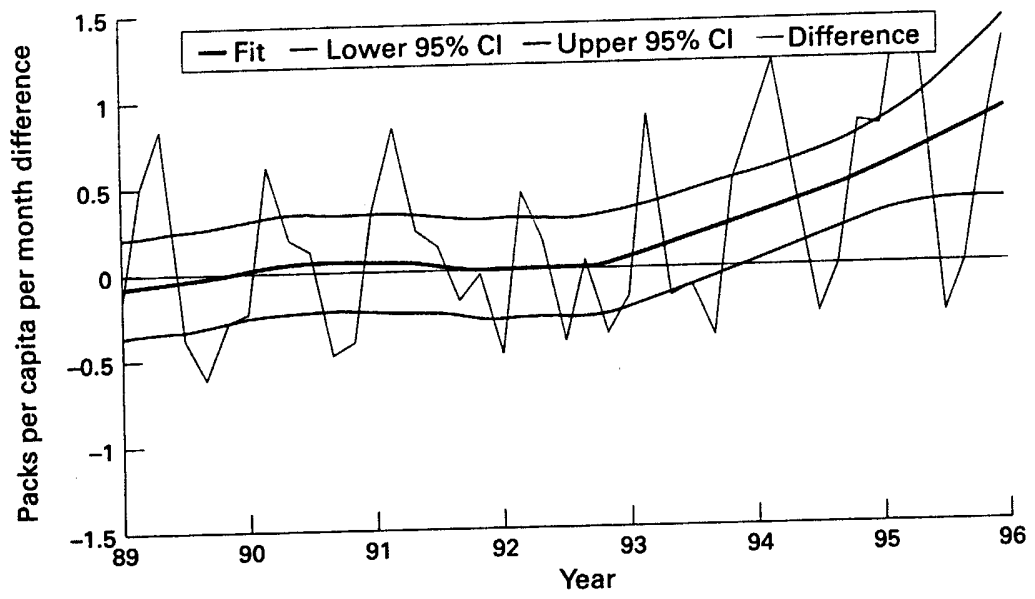

Figure 2 The thin line is the difference in raw per capita cigarette consumption between Figure 2 The thin line is the difference in raw per capita cigarette consumplitur indicate intervention states and comparison states (excluding California). Positive values indicat The lower consumption in intervention states than the comparison states for that period. The thick line is the smoothed difference (with 95\% confidence limits) in per capita cigarette

consumption for the two groups of states. Where the lower confidence
difference between the two groups of states is significant at $P<0.05$.

comparison group, a procedure that also directly removes most of the seasonal variation. Finally, we used a smoothing algorithm (Loess procedure from S-plus) which employs a bootstrap procedure allowing $95 \%$ confidence intervals $(\mathrm{CI})$ to be calculated for the smoothed trend lines. ${ }^{22}$ Although data from before 1989 were used to increase the precision of the estimates of seasonal variation for the calculation of Loess trends, the two groups of states had identical trends so these data are not included in the figures.

For the analysis of the price data, we computed the weighted yearly average inflation-adjusted price/pack of cigarettes for the intervention and comparison groups. The weights were the state adult populations, as in the per capita consumption analysis. Inflation adjustments were to 1989 dollars using regional consumer price index adjustments applied to the data from appropriate states. ${ }^{23}$ In addition to examining the trends in price for the interventon and comparison groups, we plotted the percentage change in consumption versus the percentage change in price from 1992 to 1994 for each state individually. As price is reported as of 1 November each year, we use the October-November per capita consumption data point for each state. We chose this time interval because 1992 is the last year of the planning phase for the ASSIST states and 1994 is the last year price data was available. The simple linear regression of percentage change in price versus percentage change in consumption was computed for each group of states.

\section{Results}

DESEASONALISED PER CAPITA CONSUMPTION TRENDS

There appears to be no difference in the deseasonalised per capita consumption data between the intervention and comparison groups through at least mid 1993 (figure 1). In 1989, consumption in both groups was approximately 12 packs per person per month and by 1991 it had decreased to 11 packs per person per month. However, starting in late 1993, the consumption trends start to diverge. The intervention states maintained a lower consumption rate through 1995, but the comparison group appears to show an increase in consumption.

CONSUMPTION DIFFERENCES BETWEEN GROUPS Figure 2 shows the difference in raw per capita consumption (thin line) between the intervention and comparison groups. If there is no difference between these groups of states, the data should show random fluctuation about the zero difference line. However, beginning in 1993 , there appears to be more positive than negative differences. The smoothed difference (thick line) in per capita consumption shows that 1993 was the beginning of a consistent pattern of lower per capita consumption in the intervention states. By 1994, the lower limit of the $95 \% \mathrm{CI}$ for the smoothed trend is above the zero difference line, indicating that the difference between the two groups of states, is statistically significant $(P<0.05)$. At the beginning of 1996, consumption in the intervention group was about $7 \%$ less than that in the other group.

CIGARETTE PRICE TRENDS IN THE INTERVENTION AND COMPARISON GROUPS

The weighted average inflation-adjusted price per pack for the intervention and comparison groups of states was similar from 1989 to 1992 (figure 3). Both groups experienced a drop in price from 1992 to 1993 . By 1994, the price per pack appeared to have returned to its 1992 level in the intervention group of states, although it was lower than the 1992 level in the comparison group. In 1993 the inflationadjusted price per pack for the intervention group was $\$ 0.066$ higher than the comparison group, and this differential increased to $\$ 0.126$ in 1994.

PRICE VERSUS CONSUMPTION CHANGES, 1992-1994 Figures 4 and 5 present the association between the percentage change in the inflation-adjusted price per pack of cigarettes versus the percentage change in per capita consumption between 1992 and 1994 for each individual state. In the comparison group of 


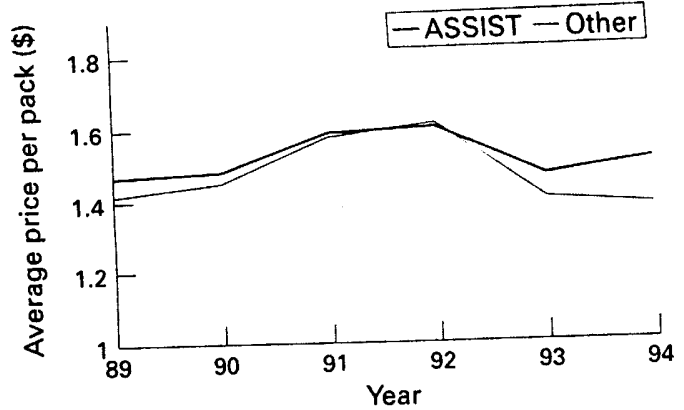

Figure 3 Trends in inflation-adjusted price/pack of Figure 3 Trends in inflation-adjisted pricelpack (excluding California).

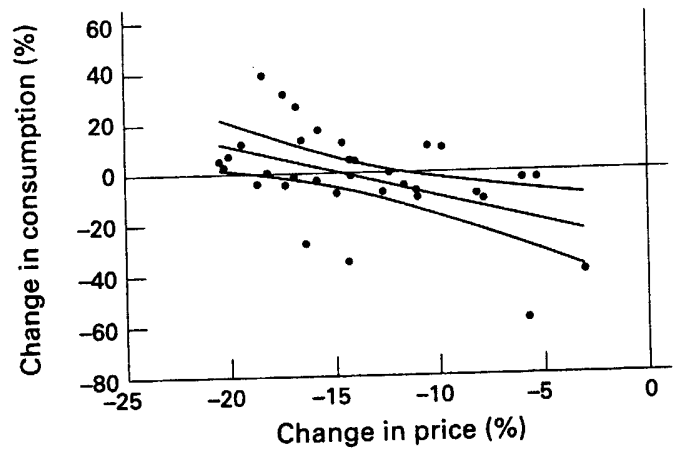

Figure 4 The percentage change in inflation-adjusted prigure 4 pack of cigarettes from 1992 to 1994 plotted against price/pack of cigarettes in per capita cigarette consumption the percentage changon states (excluding California).

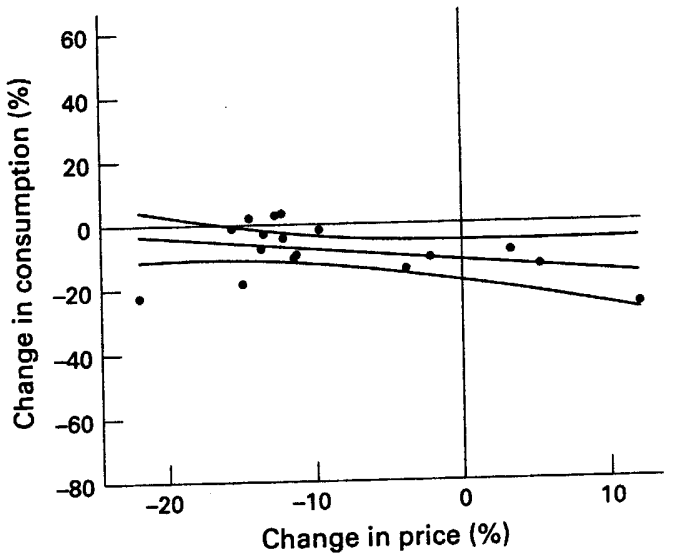

Figure 5 The percentage change in inflation-adjusted pricelpack of cigarettes from 1992 to 1994 plotted against the percentage change in per capital cigarette consumption for ASSIST states.

states, the 1994 real price of cigarettes is $5-20 \%$ lower, with 18 states showing $\geqslant 15 \%$ price decrease from 1992. No comparison state had a price increase, yet $55 \%$ showed a decrease in consumption. The slope of the regression line for perecentage change in price versus percentage change in consumption was $-2.11(95 \% \mathrm{CI}=-3.34$ to -0.80$)$.

Three intervention states show real price increases between 1992 and 1994, and only one had a price decrease of greater than $15 \%$. In each of the three intervention states with a price increase, consumption decreased as expected. In the 14 intervention states with a decrease in price, $11(76 \%)$ also had decreased consumption. In the remaining three states, the increase in consumption was very small. The slope of the regression line was $-0.39(95 \%$ $\mathrm{CI}=-0.87$ to 0.11 ) which was not significantly different from zero.

Discussion

Phase V demonstration projects such as ASSIST cannot usually be randomised, controlled trials, so it is important that the intervention group be similar to the remainder of the population on the major study measures at the time it is selected. There were no differences between the intervention and comparison groups of states in either cigarette consumption or cigarette price before state selection (1989-1990) and through the planning phase (1991-1992) of the ASSIST project. Thus, any differences observed are unlikely to be greatly influenced by selection bias.

Coincident with the beginning of the ASSIST implementation period in 1993, per capita cigarette consumption levels started to diverge between the ASSIST and comparison groups of states, becoming statistically significant in 1994. This difference has persisted through to the beginning of 1996, at which time consumption in the ASSIST states was about $7 \%$ below that of the other states. A difference is also present when Massachusetts is excluded from the ASSIST intervention group. Furthermore, the slope of the regression line in figure 1 with Massachusetts excluded is still not statistically different from zero, so the conclusions of this report are unchanged.

One possible explanation for the difference in consumption between intervention states and the others is cross-border sale of cigarettes. Cigarette companies have claimed that increases in cigarette excise taxes will result in people buying cigarettes from neighbouring states. All comparison states (except Alaska and Hawaii) border at least one intervention state. Five ASSIST states (Massachusetts, Michigan, New York, Rhode Island, and Washington) had price increases of greater than $\$ 0.15 /$ pack in 1993 or 1994 . In only one neighbouring state, New Hampshire, was there an increase in consumption during this time. Thus, it is unlikely that the overall consumption trends for the two groups of states we analysed are greatly influenced by cross-border purchasing.

As mentioned previously, the ASSIST intervention is a comprehensive tobacco control programme coordinated at the state level that included guidelines for raising cigarette excise taxes as one method of reducing consumption. However, only about $40 \%$ of ASSIST states were actually able to increase taxes in 1993 or 1994 , and in this same period, nearly a third of the comparison states also increased their tobacco taxes.' Most of these tax increases were not reflected in long-term increases in real cigarette prices. In April 1993, Phillip Morris announced an unprecedented $20 \%$ reduction in the price of premium cigarettes, and other tobacco companies quickly matched this. ${ }^{24}$ This drop in the inflation-adjusted price in both the intervention and comparison 
groups of states is reflected in figure 3 . This price decline is responsible, at least in part, for the first increase in the total American cigarette consumption observed in 1995 since the mid 1970s." Figure 1 shows that the decline in consumption was arrested in the ASSIST states and reversed in the comparison states after 1993.

Given the known relationship between cigarette price and consumption, that is, the price elasticity of demand, it is very likely that the consumption differences between the two groups of states were caused at least in part by the differences in price. However, our data suggest that price may not be the only influence on cigarette consumption in many states. The slope of the regression line for percentage change in price versus percentage change in consumption was significantly different from zero in the comparison group, but appears much diminished in the ASSIST group. Thus, compared with the other states, price seems to be a weaker correlate to consumption in the ASSIST group, which suggests a role for other influences. Such influences may be the result of other tobacco control programme elements besides taxation that may decrease tobacco consumption. As mentioned earlier, these other policy areas included worksite smoking restrictions, mass media campaigns, and smoking cessation programmes. In California, per capita cigarette consumption dropped when the increased excise tax went into effect and then dropped further when programmes supported by the new tax revenue were implemented. ${ }^{525}$ Future analysis will examine patterns of consumption in Massachusetts and other individual states.

In addition to public health programmes, cigarette consumption is influenced by tobacco company actions, including cigarette marketing. In 1993, tobacco companies spent more than $\$ 6$ billion on marketing and promotion, compared with $\$ 1.9$ billion a decade earlier. ${ }^{26}$ The fact that cigarette consumption is no longer decreasing in many states may be related to this enormous marketing budget that dwarfs the budgets of publicly funded tobacco control programmes. In addition to these marketing efforts, the tobacco industry has also disrupted the efforts of many state tobacco control programmes apparently to diminish their effect. ${ }^{27}$ This interference may continue.

At the time it was conceived, ASSIST was unprecedented in its magnitude and ambitious goals. The consumption trends observed this early in the intervention phase are very encouraging. No tobacco control effort has ever been associated with this level of difference in such a large population. Although conclusions from these trends can only be tentative, one plausible inference, which evidence from California and Massachusetts supports, ${ }^{56}$ is that reductions in tobacco use in very large populations can be achieved through comprehensive public health programmes.

This study was supported by contract 89-97872 from the California Department of Health Services, Tobacco Control Section, and by Contract CN-05295 from the National Cancer Institute.
US Department of Health and Human Services. The health consculuences of smoking: cancer. A report of the Surgeon General, 1982. Bethesda, Maryland: Public Health Service, effice on Smoking and Health, 1982 (DHHS Publication No (PHS) 82-50179.)

2 National Cancer Institute. Strategies to control tobacco use in the United States: a blueprint for public health action in the 1990s. Bethesda, Maryland: National Institutes of Health, 1991. (Publication No (NCI) 92-3316.)

3 Dwyer T, Pierce JP, Hannan CD, Burke N. Evaluation of Sydney "Quit for Life" anti-smoking campaign: part II, changes in smoking prevalence. Med $\mathcal{F}$ Aust 1986;144:344 7.

4 Pierce JP, Macaskill P, Hill D. Long term effectiveness of mass media anti-smoking campaigns in Australia. $A m ~ f$ Public Health 1990;80:565-9.

5 Pierce JP, Evans N, Farkas AJ, et al. Tobacco use in California. an eculuation of the Tobacco Control Program, 1989-1993. La Jolla, California: University of California, San Diego, Jolla,

6 Harris JE, Connolly GN, Brooks D, Davis B. Cigarette smoking before and after an excise tax increase and an antismoking campaign-Massachusetts, 1990-1996. MWWR 1996;45:966-70.

7 Anon. Monthly state cigarette tax reports. March 1983-May 1995. Washington, DC: Tobacco Institute.

8 Bal DG, Kizer KW, Felton PG, Mozar HN, Neimeyer D. Reducing tobacco consumption in California: develop ment of a statewide anti-tobacco use campaign. $\mathscr{f} A M$ 1990;254:1570-4.

9 Bal DG, Lloyd JC, Manley MW. The role of the primary care physician in tobacco use prevention and control. $C A$ 1995;45:369-74.

10 Goldsmith MF. AMA office directs smokeless states. $\mathcal{F} A M A$ 1994;271:643.

11 Institute of Medicine. Growing up tobacco free: preventing nicotine addiction in children and youth. Washington, DC nicotine addiction in children and

12 US Department of Health and Human Services. The health consequences of smoking: nicotine addiction. A report of the Surgeon General, 1988. Rockville, Maryland: Public Health Service, Centers for Disease Control, Office on Smoking and Health, 1988. (DHHS Publication No (CDC) and Heal

13 US Department of Health and Human Services. Reducing the health consequences of smoking: 25 years of progress. $A$ report of the Surgeon General, 1989. Rockville, Maryland: Public Health Service, Centers for Disease Control, Office Publich 1989. (DHHS Publication No (CDC) 89-8411.)

14 US Department of Health and Human Services. The health benefits of smoking cessation. A report of the Surgeon General, 1990. Rockville, Maryland: Public Health Service, Centers for Disease Control, Office on Smoking and Health, 1990. (DHHS Publication No (CDC) 90-8416.)

15 US Department of Agriculture. Tobacco situation and outlet report. TBS-233. Washington, DC: Commercial Agriculture Division, Economic Research Service, Department of Agriculture, December 1995.

16 Anon The tax burden on tobacco. Historical compilation. Vol. 29. Washington, DC: Tobacco Institute, 1994.

17 Cummings KM, Pachacek T, Shopland D. The illegal sale of cigarettes to US minors: estimates by state. Am $\mathcal{f}$ Public Health 1994:84:300-2.

18 US Bureau of Census. Resident population for selected age groups: 1980-1989. US Bureau of the Census, Population groups: 1980-1989. US 1990.

19 US Bureau of Census. Resident population for selected age groups: 1990-1994. US Bureau of the Census, Population Distribution Branch, 1994.

20 Becker RA, Chambers JM, Wilks AR. The new S language: $a$ 三 programming environment for data analysis and graphics. N 1988.

21 Cleveland WS, Devlin SJ. Calendar effects in monthly time series: modeling and adjustments. $f$ Am Stat Assoc $\mathrm{C}$ 1992;77:520-8.

22 Cleveland WS. Robust locally weighted regression and $C$ smoothing scatterplots. 7 Am Stat Assoc 1979;74:829-36.

23 Bureau of Labor Statistics <ftp://stats.bis.gov/pub/ time.series/cu/cu.area>

24 Shapiro E. Cigarette burn: Philip Morris price cut on Marlboro jolts industry and upsets rosey profit assumptions. Wall Street fournal 1995 Apr 5:A1,A10.

25 Hu T-W, Sung H-Y, Keeler TE. Reducing cigarette consumption in California: tobacco taxes vs an antismoking media campaign. Am $f$ Pub Health 1995;85: 1218-22.

26 US Federal Trade Commission. Federal Trade Commission 8 report to Congress for 1993. Pursuant to the Federal Cigarette Labeling and Advertising Act. Washington, DC: Federal Trade Commission, 1995.

27 Aguinaga $S$, Glantz $S$. The use of public records to interfere with tobacco control. Tobacco Control 1995;4:222-30. 